\title{
Characteristics of Choroideremia in Different Imaging Modalities: Case Report
}

\section{Heinelly Ogando Adames*}

Egresada de Instituto Tecnológico de Santo Domingo, INTEC, Residente de Cuarto Año Oftalmología, Hospital Central Fuerzas Armadas, Santo Domingo, República Dominicana

*Corresponding Author: Heinelly Ogando Adames, Egresada de Instituto Tecnológico de Santo Domingo, INTEC, Residente de Cuarto Año Oftalmología, Hospital Central Fuerzas Armadas, Santo Domingo, República Dominicana.
Received: February 02, 2020

Published: February 18, 2020

(C) All rights are reserved by Heinelly Ogando Adames.

DOI: 10.31080/ASOP.2020.03.0093

\begin{abstract}
Introduction: Choroideremia is a complex and rare disease that is frequently diagnosed due to its appearance similar to classic pigmentary retinitis.

The deterioration in visual acuity manifests in mid-adulthood, presenting nictalopia, tubular vision.

Clinical Case: Male 68 years of age who presents for presenting nictalopia, decreased visual acuity of 6 months of evolution, fundus is performed by pharmacological dilatation observing findings suggestive of choroideremia, so it is confirmed by imaging modalities Conclusion: The imaging modalities allow the early and accurate diagnosis of choroideremia to be established, thus reducing the cost of genetic testing without detracting from the value of the same, provided that it is possible to perform them.
\end{abstract}

Keywords: Choroideremia; Nyctalopia; Imaging

\section{Introduction}

Choroideremia is a complex and rare disease that is frequently diagnosed due to its appearance similar to classical pigmentary retinitis [1]. It is an X-linked recessive retinal disease that causes progressive degeneration of the retina, retinal pigment epithelium (RPE) and the choroid. Its prevalence is estimated at approximately [1]: 50,000 in people of European descent.1 Impaired visual acuity manifests itself in mid-adulthood, presenting nictalopia, tubular vision [2].

For the diagnosis of choroideremia, it is suggested to consider the following signs or symptoms of suspicion: nictalopia and concentric reduction of $\mathrm{CV}$ or tubular vision, depigmentation and progressive atrophy of RPE and choriocapillaris with visualization of the large choroidal vessels, recessive inheritance linked to $\mathrm{X}$, decreased or abolished ERG, decreased choroidal thickness measured with OCT [3].
The diagnosis is confirmed by the determination of a pathogenic variant in CHM that encodes the REP-1 protein [3]. However, the identification of characteristic findings of choroideremia in imaging modalities allows an accurate diagnosis, abolishing the high cost of genetic testing.

Its management includes periodic ophthalmological examinations to monitor the progression of CHM or the appearance of cataracts, and the use of sunglasses that block UV radiation and genetic therapy $[3,4]$.

\section{Clinical case}

Male patient 68 years of age who comes to present nictalopia, decreased progressive visual painlessness, painless and foreign body sensation of 6 months evolution. The ophthalmological evaluation presents AVSC 20/25 OD- 20/40 OS, anterior segment without relevant findings, intraocular pressure $12 \mathrm{mmHg}$ both eyes. Eye 
fundus under pharmacological dilation where generalized atrophy of the pigmentary epithelium (RPE) with pigment dispersion and pigment accumulation, excavation of 04. OD, 05 OS, peripapillary paleness and slightly thinned central emergency vessels, apparent macular thickening of both eyes, is observed. brightness in cellophane suggestive of epiretial membrane left eye.

Fluorescein angiography (Figure 1) Generalized atrophy of the RPE with pigment dispersion and areas of pigmentary accumulation, choroidal circulation with intact central island is visualized with the passage of contrast.

Optical coherence tomography (Figure 2) AO: Macular thickening (343 microns), lipid deposits and intraretinal spaces. Os: epiretinal membrane Humphrey 24-2 visual field with reliable parameters (Figure 3) Concentric reduction of the bilateral visual field, small central vision island, DM - 24.7 DB od, - 29.15 DB os.

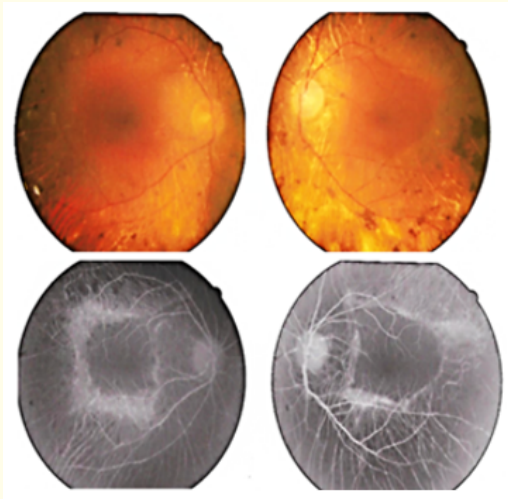

Figure 1: Generalized atrophy of the RPE with pigment dispersion and areas of pigmentary accumulation, choroidal circulation with intact central island.
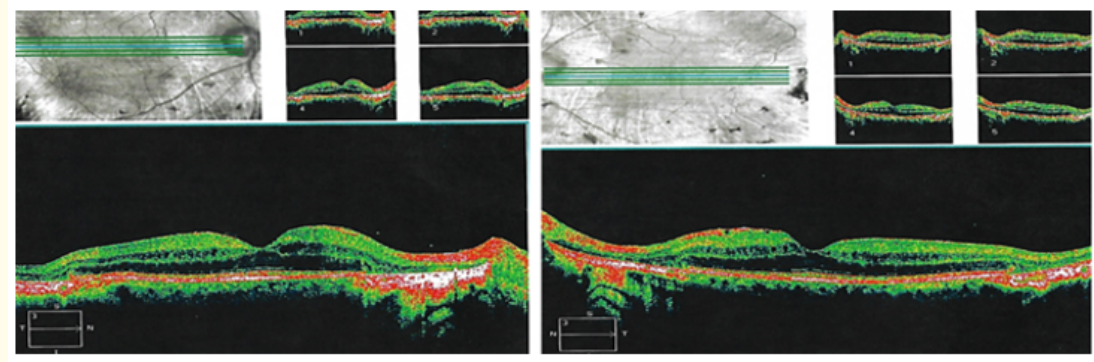

Figure 2: Macular thickening (343 microns), lipid deposits and intraretinal spaces. Os: epiretinal membrane
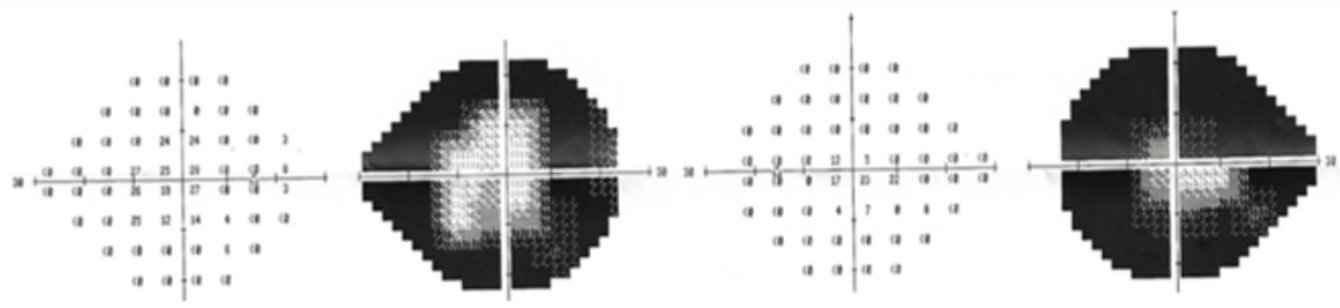

Figure 3: Concentric reduction of the bilateral visual field, small island of central vision.

Behavior: Guidance on genetic condition, general measures to prevent free radical damage, antioxidants and topical dorzolamide for macular edema management, periodic visits

\section{Discussion}

The accurate and absolute diagnosis of choroideremia is based on the identification of clinical features combined with comple- 
mentary imaging exams, however for its confirmation it is necessary to carry out genetic tests in order to determine the CHM gene alteration. REP 1, this generates a high cost for the patient, for which specific characteristics have been identified in the different imaging modalities that allow establishing the diagnosis of choroideremia, some of which were described in the case presented.

In the optical coherence tomography the following findings compatible with choroideremia have been isolated: 1) a diffuse and independent degeneration of the choriocapillaris, retinal pigment epithelium (RPE) and neural retina, 2) a primary degeneration of photoreceptors followed by RPE and choroidal atrophy. Presence of interlaminar bridges (ILB, wedge-shaped hyperreflective structures that connect the internal and external retina) and external retinal tubing (ORT, structures in the external retina composed of deteriorating photoreceptors and remaining external limiting membrane (ELM) that typically appears in OCT as hyperreflective ovoid structures with a hyperreflective light, Lazow., et al. reported a relatively abrupt termination of the internal segment / ellipsoidal area of the external segment (EZ) and the ELM that frequently coincide with ILB.

Angiographically, the scalloped areas of the missing choriocapillaris are observed, hypo fluorescent appear next to the hyperfluorescent areas of the perfused choriocapillaris. Although not a common feature, choroidal neovascularization secondary to choroideremia may develop, which leads to a neovascularization leakage characteristic [5].

Irregular island of hyper fluorescence in the fovea surrounded by a generalized absence of choriocapillaris and retinal pigmented epithelium [5].

In the perimetry, the loss of the visual field consistent with the location of chorioretinal degeneration will prevail. The earliest finding is an irregular loss of middle peripheral vision. Progressive and patchy atrophy can lead to irregular scotomas and, finally, an almost complete loss of central and peripheral vision. In advanced disease, small islands of vision can remain in the fovea and light can be perceived in the distant periphery [6].

\section{Conclusion}

We conclude on the basis of the foregoing that the imaging modalities allow the early and correct diagnosis of choroideremia to be established, thus reducing the cost of genetic tests, without diminishing the value of them, provided there is the possibility of performing them.

\section{Recommendation}

Thoroughly emphasize clinical and imaging findings to establish the diagnosis of choroideremia and appropriate management of both the patient and affected family members.

\section{Bibliography}

1. MA Genead and Fishman GA. "Cystic macular oedema on spectral-domain optical coherence tomography in choroideremia patients without cystic changes on fundus examination". Eye 25.1 (2011): 84-90.

2. TrujilloTiebas. M.J.y col. Coroideremia: Aspectos clínicos y moleculares. Rev: Mundo Científico-Médico (1997): 11.

3. Coussa RG and Traboulsi EI. "Choroideremia: A review of general findings and pathogenesis". Ophthalmic Genet 33 (2012): 57-65.

4. Khan KN., et al. "Clinical and Genetic Features of Choroideremia in Childhood". Ophthalmology 123.10 (2016): 2158-2165.

5. Campos-Pavon J and Torres-Pena JL. "Choroidal neovascularization secondary to choroideremia". Archivos de la Sociedad Espanola de Oftalmologia 90.6 (2015): 289-291.

6. McCulloch C. "Choroideremia: a clinical and pathologic review". Transactions of the American Ophthalmological Society 67 (1969): 142-195.

\section{Assets from publication with us}

- Prompt Acknowledgement after receiving the article

- Thorough Double blinded peer review

- Rapid Publication

- Issue of Publication Certificate

- High visibility of your Published work

Website: www.actascientific.com/

Submit Article: www.actascientific.com/submission.php Email us: editor@actascientific.com

Contact uS: +919182824667 